\title{
Anthony Pratkanis, Elliot Aronson Wiek propagandy. \\ Używanie i nadużywanie perswazji na co dzień Warszawa 2013, pp. 346
}

$\mathbf{R}$ ecently, we celebrated 25 years of freedom. It is a period long enough to see emotional media campaigns related to political elections or important decisions of a social nature. Due to the density of messages coming to us, we often lose a clear picture of what is information and what is already an attempt to manipulate. The media play an important role in democratic societies and they are referred to as the fourth power. On the other hand, the fear of losing independent opinion and decision is present in our lives. Therefore, are we, the citizens, still able to reflectively receive and process information? Or maybe we are already automated consumers?

These questions, and many more, are asked in the book by Anthony Pratkanis and Elliot Aronson Wiek propagandy. Używanie $i$ nadużywanie perswazji na co $d z i e n$. It applies to a much wider range of concepts than just propaganda, namely persuasion, advertising, education, social influence and manipulation. The au- thors discussed the processes resulting in changes in the behavior and attitudes of consumers. Pratkanis and Aronson in their lives witnessed many cases extensively publicized by the media (for example, Bill Clinton's personal life). They claim that many people have been discouraged from television and ceased to believe in the information it transmitted. The reason for writing this book was to show different techniques of manipulation and the citizens' raising awareness of their use.

The authors distinguish two categories of influence: persuasion and propaganda. While persuasion is bidirectional and involves an exchange of arguments and discussion between speakers and listeners, propaganda is a communication from one point of view. It is not a new phenomenon, although many associate it with the twentieth century. Propaganda is as old as the civilization. Already early Egyptian hieroglyphics presented history in a way favorable to the ruling class. With 
this introduction the authors start a long and interesting history of ways of persuasion. In what way are we different from the citizens of ancient Greece or Rome? The understanding of persuasion they considered as an elementary skill. Nowadays we have lost this ability.

An important aspect of the work is dealing with the conflict between the desire to be informed and tailored to the model presented by the various media. Although we can see that our opinions are the result of external influences, we believe that others are more susceptible to influence. The authors explain this phenomenon as the expectations of the audience. Everyone expects that the message will show our point of view, if it is one-sided we think that it favors the opposing party. Pratkanis and Aronson convince the reader (by showing various test results) how deeply the media pervade human life and how much influence they have over seemingly independent decisions. On the other hand, they show the role of the mass media in contemporary culture, clearly separating persuasion, education and propaganda in the strict sense. They also show how to deal with the killing of thinking and democracy propaganda.

At the beginning of the book the authors present the picture of the world in which we live. Although instinctively we associate persuasion with advertising, it is present in almost all occupations. Almost every major politician employs political experts who advise him on how to convince the audience.

In the first step in the analysis of the method of persuasion it is appropriate to prepare the ground. Words have a significant impact on people. The authors show us that the way in which the object is determined directs our thoughts and reac- tions associated with it. As aptly described by the psychologist Gordon Allport, the nature of language is to share and categorize the humming buzz of information that affects us every day ${ }^{1}$. Many of the cited studies show how important specific terms and labels are for human behavior. Even a weed under a different name could become a rose.

In the next step the importance of the message sender is discussed, that is how important, for our attitude, is the person who provides information. It is interesting that assumptions about the impact of prestige on the effectiveness of persuasion were formulated in ancient times. Of course, it is also possible to fabricate credibility. Also the message is frequently an element of manipulation. Authors mentioned such issues as packaging, how to convince ourselves about life and imagery of message, distraction or repetition of advertising. A lot of attention is devoted to emotions: fear, guilt, the phenomenon of unavailability and magic objects of desire.

In an easy and accessible way we can learn about many social and psychological theories. All concepts are carefully explained. The reasoning of Pratkanis and Aronson is clear and comprehensible, individual chapters and sections form a coherent whole. The book is written in a very interesting and lively way, which facilitates its reception. Not only authors but also translators deserve recognition, as their work is excellent and facilitates the reception of the book.

Almost every element of the presented theory is reflected in the examples of social behavior or empirical research. Although

A. Pratkanis, E. Aronson, Wiek propagandy. Używanie i nadużywanie perswazji na co dzień, Warszawa 2013, p. 69. 
the authors are well-known psychologists, they also refer to the extensive literature of the subject. Pratkanis and Aronson recall the results of the research of such experts as J. Zaller, W. Lippmann, E. Fromm, P. Zimbardo, and many others. However, the theory proposed by the authors could be transposed to the Polish examples. Almost all of the studies cited by the Pratkanis and Aronson were conducted in the United States. European links relate to the Nazi propaganda, Stalin and other totalitarian systems. It is worth to note that the authors cited the study conducted in Poland by Dariusz Doliński and Richard Nawrat ${ }^{2}$. Readers unsatisfied with native examples have recourse to Polish literature, which is extensive.

We primarily associate propaganda with totalitarian systems, where one person or party has control over all areas of life. The authors argue that such an absolute control is not needed to convince us to do something that is not entirely rational. Wiek propagandy is a book terrifying in a way, because if one actually uses the techniques of persuasion, one can convince people to condone to the most absurd behavior. The man seems to be a puppet which can be easily guided. Pratkanis and Aronson extensively develop the topic

\footnotetext{
2 Ibidem, pp. 184-185.
}

of similarities between modern education and propaganda. Selection of messages is the beginning of propaganda and we meet with this at every step.

Is there a way to protect ourselves from the described manipulation and propaganda? Pratkanis and Aronson consider that knowledge of the mechanism of influence is a good first step to strengthen resistance to propaganda but not enough to completely protect ourselves. If one wants to be a rational citizen in a democratic society, one must avoid having a single source of information, receive messages reflectively, and be wary of influence in the issues that in the political life would be open to discussion. Thus, it is not a book only for representatives of the scientific community interested in the discussion about the media but also for every citizen involved in political life, who wants to more consciously receive information from the surrounding world. Conclusions drawn from the work are not limited to the world of politics, or the media, but may be used in commerce, justice or everyday life. This is probably why this book still generates a lot of interest and its circulation is resumed. Although Pratkanis and Aronson are world-renowned American psychologists, this book will certainly interest students of journalism, political science, sociology and pedagogy. 